\title{
Employing the Internal Marketing Theory to Explain How Knowledge Dissemination Can Be Enhanced in Organizations
}

\author{
Sheron Lawson \\ Wayland Baptist University
}

Knowledge dissemination has been found to contribute positively to a firm's performance. The internal marketing theory was employed to investigate how knowledge can be effectively disseminated in organizations to enhance organizational performance and innovation. The results indicated that a social learning environment is imperative to the knowledge dissemination process.

\section{INTRODUCTION}

Many researchers now agree that knowledge management is more than just the storage and manipulation of information, but a process that requires the commitment to create and disseminate knowledge through the organization (Parikh, 2001; Marshall et al., 1996). Lawson (2013) in utilizing the Knowledge Management Assessment Instrument (KMAI) that assesses the six dimensions of knowledge management found that the dissemination and application dimensions had the most significant influence on organizational performance and innovation. Van der Bij, Song \& Weggeman (2003) stated that knowledge dissemination is of crucial importance to new product development because it offers a clear overview of market needs, technology developments and competitors' actions. They further stated that it leads to quick awareness of the external and internal activities therefore, leading to a high quality of improvisation.

Lawson (2003, p.12) described knowledge dissemination "as knowledge that is personalized and distributed in a useful format to meet the specific needs of users. The knowledge is articulated in a common language and using tools that are understood by all users". Van der Bij et al. (2003) described knowledge dissemination as a process of technological information exchange which can occur formally and informally and both horizontally and vertically. Ramirez, Morales \& Rojas (2011) empirical evidence indicated a positive and direct relationship between organizational learning and performance and the four modes of knowledge conversion. Nawaz, Hassan, \& Shaukat (2014) empirical findings also showed direct and significant relationship between knowledge management practices and firm performance and innovation.

\section{Problem Statement}

Knowledge dissemination has been found to contribute positively to a firm's innovative performance (Lawson, 2013; Lofsten, 2014; Jafari et al, 2014; Ramirez et al. 2011; Nawaz et al 2014; \& Shankar \& Gupta, 2005). Yet, there is still the need to gain greater understanding of how knowledge can be effectively disseminated throughout the organization. Ramirez et al. (2011) posited that it is important 
that organizations have knowledge management systems that equip the company with greater ability to anticipate and to be more flexible to increasing changes taking place in the competitive environment. Bergquist \& Ljungberg (2001) purported that for the effective dissemination of knowledge, attention must be given to the interactive process of communication, negotiation and reviewing. They further stated that it is a social process and that there must be an understanding of the organizational context and quality group support.

The objective of this research is to investigate how knowledge dissemination can be enhanced in organizations thereby leading to sustained performance and innovation. It is proposed that a social learning environment with effective communication flows can influence the effective dissemination of knowledge.

Some communication researchers have asserted sociological implications in the communication process. Communicationtheory.org (n.d) highlighted two such models, the Schramm model of communication and the Rileys' model of communication. Schramm (1954) communication model points out that for successful communication the sender and the receiver must have something in common. The model includes a common area (field of experience) where communication is possible. The Rileys' communication model points out the important roles of primary groups and reference groups in communication. The reference group is where a person may define his attitudes, values and behavior. The primary groups are distinguished by the level of intimacy and members can influence the attitude and behavior of each other in a degree by the larger social structure. The expectation is that the social characteristics and backgrounds of the primary social groups will be reflected in the message sent and likewise, the receiver will receive the message as a member of his primary sociological groups.

Internal marketing theory corroborates the social implications of the communication process and how effective flows can impact organizational effectiveness and innovation. Óorié \& Vokic (2009) \& Spitzer $\&$ Swidler (2003) described internal marketing as a manager-employee relationship where the employee is an internal customer. For information to be effectively disseminated there must be an atmosphere of trust and support and the employees must be esteemed as valuable stakeholders and granted autonomy and respect to perform their duties (DeBussy, Ewing, \& Pitt 2003)

\section{Purpose Statement}

The purpose of this research is to employ the internal marketing theory as theoretical framework to investigate how knowledge can be effectively disseminated in organizations to enhance and increase organizational performance and innovation. Since the early 1990s knowledge management has been a critical factor for organizations looking to increase their productivity and effectiveness (Delong \& Fahey, 2000; Zack, 1999; Inkpen, 1996). Inkpen (1996) propounded that organizations' failure to create and manage knowledge as a critical asset may account for their declining performance. A competitive marketplace dictates that organizations must be innovative to stay in business. The effective dissemination of organizational knowledge can help in the competitive advantage of organizations. Therefore, organizations must search for innovative ways to ensure that internal mechanisms are in place to allow for effective flow of information and knowledge (Lofsten, 2014; Jafari et al, 2014; Ramirez et al., 2011; Nawaz et al 2014; \& Shankar \& Gupta, 2005).

The research employed an in-depth review of literature method to garner greater information and insight on the knowledge dissemination process. Empirical findings from peer-reviewed journal articles were reviewed, and a theoretical framework was constructed to reveal the findings. The internal marketing concepts and communication elements were correlated to findings on elements that contributed to effective knowledge dissemination. The integrative framework that was devised, highlighted a composition of elements that influence effective disseminate and flow of knowledge that could be translated to improved performance and innovation. 


\section{Propositions}

Proposition 1: Internal Marketing helps to cultivate a social learning environment that will lead to improved communication flow - In an environment where there is a positive collaborative relationship between managers and employees, a social learning environment will be cultivated. In such an ethical and trusting organizational climate, where the employees are treated as valued stakeholders and esteemed customers, they will develop positive attitudes and efficacious behaviors.

Proposition 2: Social Learning environment leads to effective communication flow - An environment that is engendered with trust, cooperation, autonomy, flexibility, incentives and mutual support will lead to enhanced internal dialogue and boost participation.

Proposition 3: Social learning environment with effective communication flow can influence effective dissemination of knowledge - Effective dissemination of knowledge requires a social learning environment that is based on trust, shared understanding and commitment.

\section{LITERATURE REVIEW}

\section{Internal Marketing and Communication}

Internal marketing concept is a management philosophy that is the convergence of several previously separate business areas and techniques, such as strategic management, quality management, human resource management, corporate communications and customer relationship marketing that is based on the idea of employees as internal customers (Óorié \& Vokic, 2009). DeBussy, Ewing, \& Pitt (2003) purported that internal marketing requires employees to be treated as internal customers and as such creating an ethical organizational climate and a concomitant atmosphere of mutual trust. They posited the recognition of the employees as key stakeholders offers the potential for greatly enhanced organizational effectiveness.

Óorié \& Vokic (2009) stated the internal marketing philosophy implementation should be a collaborative effort led by top management where employees are made aware of their contribution to serving external customers. They further stated that particular employees' attitudes and behaviors are required to convey the appropriate message to customers. Fleming \& Artis (2013) emphasized that the managers' role is very important in the communication process and influences the signal that the employees are receiving and the messages that are eventually pass to the customers. They stated that managers must be cognizant of their own feelings toward the message and the employees' attitudes when they are sharing information. Managers, Fleming \& Artis (2013) stated, may need to spend more time communicating the message to those whose personal attitudes are not in line with the message that the firm is trying to convey to customers.

Spitzer \& Swidler (2003) posited that internal communication represents the core of managementemployee relationship. It encompasses a multidimensional set of elements and has three basic objectives. The first objective is that the employees understand and accept the content, intent, relevance, and merit of the message that is communicated to them. The second objective is that the employees achieve the goals of the communications with regard to motivating, directing, informing, or gaining their participation. The last objective is that the end result of an improved internal dialogue is achieving improvement in one or more of the core success components such as product quality, sales, profitability, workforce performance and satisfaction, and, ultimately, customer satisfaction. Škare \& Kostelić (2015) suggested that from the internal marketing perspective, the productivity of an individual can increase due to lifelong learning and training. They further stated that internal marketing serves as a synonym for training and motivation of employees, which represents sets of efforts in finding, keeping and developing of the employee.

Schüller \& Chalupský (2011) in their research on internal marketing and communication concluded that it is beneficial for organizations such as universities to place more emphasis on non-financial motivational tools such as training courses, teambuilding and informal meetings. The authors further 
recommended an environment that provides support services by top management and that give employees ample autonomy to perform their duties. Roșca (2017) stated the importance of internal marketing within a sport club and that it is justifiable to implement its philosophy within the communication flow of the organization because it regulates what happens. The study suggested that internal communication that is efficacious, clear and focused the mission upgrades leadership style, boost participation and increase commitment, which translates to a highly esteemed work ethic and faith towards manager. Roșca (2017) further stated that when managers communicate a culture of winning and enter a close relationship of collaboration in which they become coaches, mentors and leaders, they have high impact on the performances of athletes.

DeBussy, Ewing, \& Pitt (2003) purported that a dialogic or two-way communication environment where trustworthiness and cooperativeness exist between management and employees offers a potential framework for empowering employees to enhance organizational performance. Pažeraité, \& Repovienė (2018) concluded that communication which uses relevant and reliable content meets the requirements for time delivery, eligibility, creditability and responsibility which are related to the characteristics of effective internal communication. The authors cited examples of how short videos and infographic can help to promote in employees a positive sense of belonging and turn on the capability to develop employees' understanding of the organization aims.

In summary internal marketing and social communication is described to be a positive collaborative relationship between managers and employees that is cultivated in social learning environment. An environment that is engendered with trust, cooperation, autonomy, flexibility, incentives and mutual support. In such an ethical and trusting organizational climate, where the employees are treated as valued stakeholders and esteemed customers, they will develop positive attitudes and efficacious behaviors (Óorié \& Vokic, 2009; Spitzer \& Swidler, 2003; Fleming \& Artis, 2013; Škare \& Kostelić 2015; \& Schüller \& Chalupský, 2011). In this climate communication flow is enhanced and the transfer and sharing of knowledge is increased which can lead to improved job satisfaction and performance (DeBussy, Ewing, \& Pitt, 2003; Roșca, 2017; \& Pažèraitè, \& Repovienè, 2018).

\section{Knowledge Management Dimensions}

Gupta et al. (2000, p17) defined knowledge management as "a process that helps organizations find, select, organize, disseminate, and transfer important information and expertise necessary for activities such as problem solving, dynamic learning, strategic planning, and decision making". Lawson (2003) developed the knowledge management assessment instrument (KMAI) that assesses six dimensions of knowledge management - creation, capture, organization, storage, dissemination and application. According to the knowledge management literature (Inkpen, 1996; Wigg, 1993; Beckman, 1999; Parikh, 2001) an organization is said to be actively managing their knowledge assets when it effectively incorporates these processes into its organization strategic management system. Kingston (2012) said that knowledge dissemination is a crucial part of knowledge management because it ensures that knowledge is available to those you need it. Lawson, (2013); Lofsten, (2014); Jafari et al. (2014); Ramirez et al. (2011); Nawaz et al (2014); \& Shankar \& Gupta, (2005) found that the dissemination dimension contributed significantly to organizations' increased performance and innovation. Knowledge management is a continuous process and becomes an expanding spiral as more and more knowledge is added and managed over time (Parikh, 2001). Moore (1998) stated that fostering a knowledge-sharing culture is the most important critical success factor for knowledge management projects.

\section{Knowledge Dissemination}

Wang, Chiang \& Tung (2012) stated that knowledge dissemination is when members in an organization receive and share information with each other. These interactions, they stated, will lead to creation of new knowledge which will eventually forms a system that leads to routine activities. A company's routine practices, along with documentation and commercial secrets are the primary sources for competitive advantage. Organizational learning and Human Resource Management (HRM) principles are used to strengthen the employees' ability to acquire knowledge, therefore, the integration of HRM and 
knowledge management is one of the important imitative in business operations (Wang, Chiang \& Tung, 2012). Simonin and Ozzsomer (2009) research findings verified the link between knowledge dissemination and human resources practices. Sustained training of managers created an environment of shared understanding and encouraged managers to act as coaches and mentors. This learning environment enhanced knowledge processing capacity. They highlighted that rewards also played a role in knowledge transfer. In the global organizations, when expatriates' presence is limited, rewards plays a higher role in knowledge activities. In expatriates' presence there is a greater propensity to share market knowledge.

Janz \& Prasarnphanich (2003) stated that the effective flow of knowledge is based upon trust at both the individual and organizational levels. Organizations, they stated, that provide a climate of trust which is built on a culture that embraces and rewards knowledge-sharing in all its manifestations such as learning, mentoring, collaboration, and ideas sharing facilitate knowledge creation and dissemination. Janz \& Prasarnphanich (2003) concluded that cooperative learning and autonomy, allowing knowledge workers to have the freedom to exercise authority and elevating a supporting work climate lead to strong work satisfaction and ultimately organizational performance.

Bergquist \& Ljungberg (2001) concluded for optimal dissemination of information, a peer review process is most beneficial because it ensures that relevant new knowledge is disseminated to the different and pertinent parties. Peer review is described by Bergquist \& Ljungberg (2001) as an organizational process of how knowledge becomes socially anchored in an organization. Members provide their interpretations of certain cases and obtain feedback from other members, which in turn generates what is socially accepted as knowledge. Evans \& Alleyne (2009) extended the knowledge domain model (KDM) which attempts to bridge two views of knowledge. One is that knowledge is highly complex and difficult to model, and the other is that knowledge can be easily modeled by applying a system view to address the analysis of knowledge processes. KDM elucidates that organizational context, groups, organizational events and artifacts, individual knowledge and the concept of time influence knowledge construction and dissemination. Organizational context helps individuals and groups to understand initiatives and practices and, guides the development of good behavior, information sharing and good decision making.

Shankar and Gupta (2005) created an integrated knowledge management model that advocates cycles of knowledge processes at the individual, group, collaborators levels. The framework highlighted how unstructured, semi-structured and structured knowledge can be captured across the organization. Unstructured knowledge is application learning through individual and group. This type of knowledge is captured through communication between teams. For optimal capture of knowledge, incentives should be in place for individuals and teams to document their experiences. They further stated that the cyclic approach of knowledge capture and sharing can facilitate access for employees, customers and collaborators. Gupta \& Roche (1997) identified models of knowledge acquisition and dissemination. They discussed how groups such as Communities of Practice and Share Groups are transforming knowledge acquisition, creation, packaging and dissemination. The characteristics for these groups are that knowledge is integrated in the life of the communities and learning is fundamentally a social phenomenon. The process of learning and membership is inseparable and the ability to contribute to the community creates the potential for learning.

Kelliher, Harrington, \& Galavan (2010) discussed the need for a practitioner-academic partnership in knowledge dissemination from leader to undergraduate students. They proposed a participatory leader knowledge dissemination model in which the leader involvement promotes skills development and stimulates a dynamic collaborative process with evolution of knowledge transfer among the students. Kvedaravicius, Bakanauskas \& Bakanauskiene (2005) research findings suggested that mediators are needed for knowledge dissemination and the need to invest in knowledge accessibility process to develop a knowledge economy. They stated that for effective dissemination, there needs to be informed users, centralized knowledge dissemination and knowledge dissemination centers. Moore \& Birkinshaw (1998) highlighted how Centers of Excellence were used to leverage knowledge and represent the best practice of knowledge development and dissemination. New knowledge was built through the interaction of professional employees. They concluded that the Centers of Excellence model is attractive because it provides the focal points for knowledge development and dissemination. The characteristics of the centers 
are top management has strategic role which is less intrusive, and incentive and motivation issues were central to making the model effective. The day to day and high-profile nature of the work resulted in high peer recognition.

Summary of findings from the review of empirical literatures on knowledge dissemination revealed that effective dissemination of knowledge requires a social learning environment that is based on trust and shared understanding. Autonomy and freedom to exercise authority and sharing information are requirements. The role of top management is very important and should be collaborative participatory partnership between managers and the subordinates. The flow of knowledge will be more effective if managers act as coaches and mentors (Kelliher et al 2010; Shankar and Gupta 2005; Bergquist \& Ljungberg (2001; \& Janz \& Prasarnphanich, 2003).

There is a verified link between HRM practices and knowledge management. The involvement is beneficial at all levels of the organization including the individual, group and organizational context. Communities of practice and centers of excellence that convey an organizational climate of cooperative learning, employee interaction and peer recognition play integral roles in the transfer and dissemination of knowledge. Centralized dissemination centers and knowledge disseminators were also cited as being integral in the knowledge dissemination process (Moore \& Birkinshaw,1998; Kvedaravicius et al 2005; \& Gupta \& Roche, 1997).

\section{DISCUSSION AND CONCLUSION}

The results from knowledge dissemination researches corroborate with internal marketing theory that effective communication strategies enhance the dissemination of information and hence the improvement in organizational performance. Internal marketing theory states that employees must be treated as internal customers in an environment that exudes trust, respect and support. Managers must be encouraging and instilling positive values and organizational mission in employees.

The results were combined to devise an integrative framework that includes the elements of internal marketing, communication process, knowledge dissemination. The framework elucidates that a social learning environment is imperative to the knowledge dissemination process. The following elements must be established in an organization for effective dissemination of knowledge, life-long learning, supportive top management, an environment with shared understanding that instills positive attitudes and winning culture to the employees, employees' incentives and reward system, managers that are mentors and coaches and communication flow that is clear and focused on the firm's mission.

The integrative framework highlights the findings from the literature that if the listed elements are in place, organizations will see marked improvement in employee receiving and applying knowledge that will lead to improvement in performance and innovation that can boost competitive edge. 


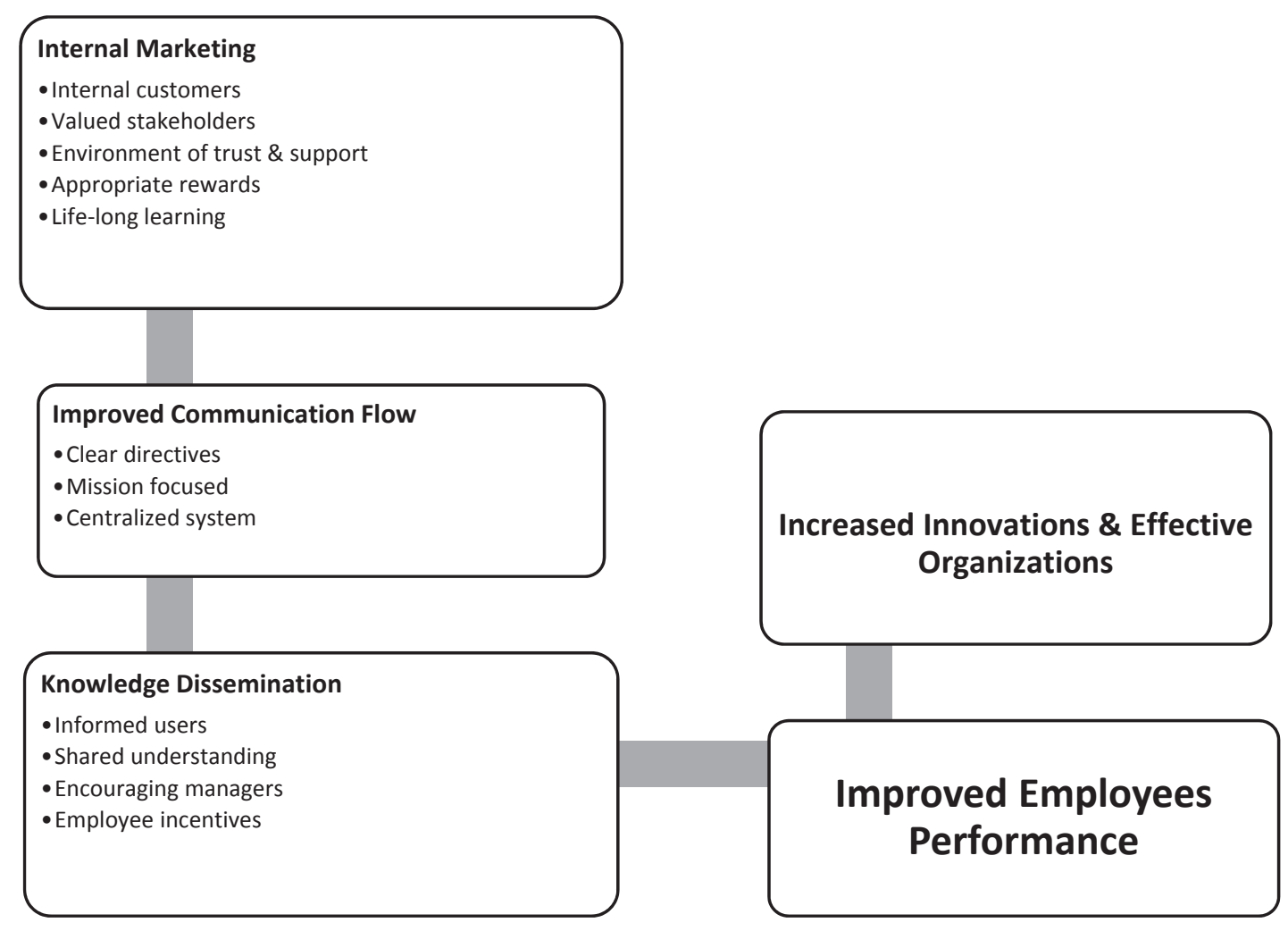

\section{REFERENCES}

Beckman, T. J. (1999). The current state of knowledge management. Knowledge Management Handbook, edited by J. Liebowitz. Boca Raton, CRC Press.

Bergquist, M., \& Ljungberg, J. (2001). Practising peer review in organizations: a qualifier for knowledge dissemination and legitimization. Journal of Information Technology, 16, 99-112.

Coric, D.S., \& Vokic, S.P. (2009). The roles of internal communications, human resource management and marketing concepts in determining holistic internal marketing philosophy. Zagreb International Review of Economics \& Business, 12(2), 87-105.

De Bussy, N.M., Ewing, M.T., \& Pitt, L.F. (2003). Stakeholder theory and internal marketing communications: A framework for analyzing the influence of new media. Journal of Marketing Communications, 9, 147-161.

DeLong, D. W., \& Fahey, L. (2000). Diagnosing cultural barriers to knowledge management. The Academy of Management Executive, 14(4), 113-129.

Evan, M. M., \& Alleyne, J. (2009). The concept of knowledge in KM: A knowledge domain process model applied to inter-professional care. Knowledge and Process Management, 16(4), 147-161.

Fleming, D.E., \& Artis, A.B. (2013). The role of the manager in shaping customer contact employee perceptions of the firm's relationship with technology: A conceptual model. Services Marketing Quarterly, 34, 126-138

Goffin, K., \& Koners, U. (2011). Tacit knowledge, lessons learnt, and new product development. Journal of Product Innovation and Management, 28, 300-318.

Gupta, A., \& Govindarajan, V. (2000). Knowledge management's social dimension: Lessons from Nucor Steel. MIT Sloan Management Review, 42(1), 71-80. 
Gupta, B., Iyer, L.S., \& Aronson, J.E. (2000). Knowledge Management: practices and challenges. Industrial Management + Data Systems, 100(1), 17-21.

Gupta, V. K., \& Rohe, D. (1997). Managing knowledge: A community of re-engineering practice in Houston. Knowledge and Process Management, 4(3), 177-186.

Inkpen, A. C. (1996). Creating knowledge through collaboration. California Management Review, 39(1), 123-140.

Jafari, S. M., \& Suppiah, M. (2014). The effect of knowledge management practices on employees' innovative performance. The International Journal of Management Science and Technology, Special Issue: ICIE, 82-93.

Janz, B., D., \& Prasarnphanich, P. (2003). Understanding the antecedents of effective knowledge management: The importance of a knowledge of a knowledge-centered culture. Decision Sciences, 34(2), 351-384.

Kelliher, F., Harrington, D., \& Galavan R. (2010). Spreading Leader Knowledge: Investigate a participatory mode of knowledge dissemination among management undergraduates. The Irish Journal of Management, 16(17), 107-125.

Kingston, J. (2012). Choosing a knowledge dissemination approach. Knowledge and Process Management, 19(3), 160-170.

Kvedaravicus, J., Bakanauskas, A., \& Bakanauskiene, I. (2005). The development of knowledge dissemination and accessibility process in Lithuania. Knowledge-Based Economy: Management of Creation \& Development, 159-175.

Lawson, S. (2003). Examining the relationship between knowledge management and organizational culture. Doctoral Dissertation. Nova Southwestern University (UMI No. 3100959).

Lawson, S. (2013). Analysis of Knowledge Management and Market culture in Jamaica. Journal of International Politics and Development, 11(1\&2), 179-197

Lefebvre, B., Gauthier, G., Tadie, S., Duc, T.H., \& Achaba, H. (2005). Competence ontology for domain knowledge dissemination and retrieval. Applied Artificial Intelligence, 19, 845-859.

Lofsten, H. (2014). Information structures and business performance - Implications for technology-based firm's innovation performance. Knowledge and Process Management, 21(4), 246-259.

Marshall, C., Prusak, L., \& Shpilberg, D. (1996). Financial risk and the need for superior knowledge management. California Management Review, 38(3), 77-79.

Moore, C. (1998). KM meets BP: Knowledge management efforts will flop unless they are tied to business process. CIO, 12(4), 65-68.

Moore, K., \& Birkinshaw, J. (1998). Managing knowledge in global service firms: centers of excellence. Academy of Management Executive, 12(4), 81-92.

Mukherjee, A. S., Lapre, M. A., \& Van Wassenhove, L. N. (1998). Knowledge driven quality improvement. Management Science, 44(11), S35-S49.

Nawaz, M. S., Hassan, M., \& Shaukat, S. (2014). Impact of knowledge management practices on firm performance: Testing the mediation role of innovation in the manufacturing sector of Pakistan. Pakistan Journal of Commerce and Social Sciences, 8(1), 99-111.

Organizational Theories. (n.d.). Transformational Leadership Theory. Retrieved from https://www.communicationtheory.org/

Parikh, M. (2001). Knowledge management framework for high-tech research and development. Engineering Management Journal, 13(3), 27-33.

Pažèraitè, A., \& Repovienė, R. (2018). Content Marketing Decisions for Effective Internal Communication. Management of Organizations: Systematic Research, 117-130.

Prado-Gasco, V., Pardo, I. Q., Calabuig-Moreno, F. \& Vveinhardt, J. (2015). Knowledge Management in R\&D teams at a Spanish Technical Univeersity: Measurement and relations with organizational culture. Inzinerine Ekonomika-Engineering Economics, 26(4), 398-408.

Ramirez, A. M., Garcia Morales, V. J., \& Rojas, R. M. (2011). Knowledge creation, organizational learning and their effects on organizational performance. Inzinerine Ekonomika-Engineering Economics, 22(3) 309-318. 
Roșca, V. (2017). Using internal marketing communications to improve HRM in service-based sports organization. Review of International Comparative Management, 18(4), 406-420.

Schüller, D., \& Chalupský, V. (2011). Internal marketing communication of higher education institutions. Economics and Management, 16, 1316-1322.

Shankar, R., \& Gupta, A. (2005). Towards framework for knowledge management implementation. Knowledge and Process Management, 12(4), 259-277.

Simonin, B. L., \& Ozsomer, A. (2009). Knowledge processes and learning outcomes in MNCS: An empirical investigation of the role of HRM practices in foreign subsidiaries. Human Resources Management, 48(4), 505-530.

Sivakumar, P. (2012). Knowledge production \& dissemination: An analysis in the context of the National Youth Policy. Journal of Management \& Public Policy, 4(1), 33-41.

Škare, M., \& Kostelić, K. (2015). Interpersonal communication in the internal Marketing: bounded rationality game theory Approach. Economic Computation and Economic Cybernetics Studies and Research, 4, 127-149.

Skok, W., Clarke, K., \& Krishnappa, S. (2013). Managing organizational knowledge: A case study of a global energy consulting group. Knowledge and Process Management, 20(3), 123-130.

Song, M., Berends, H., van der Bij, \& Weggeman, M. (2007). The effect of IT and co-location on knowledge dissemination. Journal of Product Innovation Management, 24, 52-68.

Spitzer, R., \& Swidler, M. (2003). Using a marketing approach to improve internal communications. Employment Relations Today, 69-82.

Starkey, K., \& Madan, P. (2001). Bridging the relevance gap: Aligning stakeholders in the future of management research. British Journal of Management, 12(Special Issue), S3-S26.

Steyn, E., Steyn, D., \& van Rooyen, M. (2011). Internal Communication at DaimlerChrysler South Africa: A Qualitative Perspective on Two-Way Symmetrical Communication and Internal Marketing. Journal of Marketing Development and Competitiveness, 5(4), 131-144.

Tan, H.C., et al. (2007) Development of a methodology for live capture and reuse of project knowledge in construction. Journal of Management in Engineering, 23:1(18), 18-26.

Van der Bij, H., Song, X.M., \& Weggeman, M. (2003). An empirical investigation into the antecedents of knowledge dissemination at the strategic business unit level. Journal of Product Innovation Management, 20, 163-179.

Van Gelderen, E., \& Huij, J. (2014). Academic knowledge dissemination in the mutual fund industry: Can mutual funds successfully adopt factor investing strategies? The Journal of Portfolio Management, Summer, 157-167.

Wang, L., Chang, C., \& Tung, C. (2012) Integrating human resource management and knowledge management: From the viewpoint of core employees and organizational performance. International Journal of Organizational Innovation, 5(1), Summer, 109-137.

Wigg, K. (1993). Knowledge Management Foundations. Texas: Schema Press

Zack, M. H. (1999). Managing codified knowledge. Sloan Management Review, 40(4), 45-56. 